\title{
The four-year functional result after a displaced subcapital hip fracture treated with three different surgical options
}

\author{
George Mouzopoulos • Michalis Stamatakos • \\ Helen Arabatzi • George Vasiliadis • George Batanis • \\ Anastasia Tsembeli • Mathaios Tzurbakis • \\ Michalis Safioleas
}

Received: 25 November 2006 /Revised: 6 December 2006/Accepted: 16 December 2006 /Published online: 13 March 2007

(C) Springer-Verlag 2007

\begin{abstract}
According to the literature, hip function after hip fracture is affected by the type of surgery. Our aim was to determine the correlation between surgical treatment of hip fracture and postoperative function in the elderly. Inclusion criteria were displaced hip fracture and age over 70 years. One hundred and twenty-nine participants were randomly divided into three groups according to the type of the
\end{abstract}

\author{
G. Mouzopoulos $\cdot$ M. Tzurbakis \\ 1st Orthopaedic Department, Evangelismos Hospital, \\ Athens, Greece \\ M. Stamatakos $\cdot$ M. Safioleas \\ Department of General Surgery, Laiko Hospital, \\ University of Medical School of Athens, \\ Athens, Greece \\ H. Arabatzi \\ 2nd Surgical Department, General Hospital Elpis, \\ Athens, Greece \\ G. Vasiliadis \\ 3rd Neurology Department, Papanikolaou Hospital, \\ University of Medical School of Thessaloniki, \\ Thessaloniki, Greece \\ G. Batanis \\ Pathology Department, Ahepa Hospital, \\ University of Medical School of Thessaloniki, \\ Thessaloniki, Greece

\section{A. Tsembeli} \\ Nurse Division of Attikon Hospital, \\ University of Medical School of Athens, \\ Athens, Greece \\ G. Mouzopoulos $(\bowtie)$ \\ Kanari 23, Ag. Antonios Peristeri Attikis, \\ Athens 12131, Greece \\ e-mail: gmouzop@yahoo.gr
}

surgical operation they underwent (hemi-arthroplasty [Merete, Berlin, Germany], total arthroplasty [Plus; De Puy, Warsaw, IN, USA] and internal fixation [Richards plate screw; Smith \& Nephew, Memphis, TN, USA]). The function of the patients was estimated using the following parameters: the Barthel Index and Harris Hip Score, the range of passive hip motion, the gait speed of individuals, after 1 and 4 years of follow-up. The Barthel Index scores after 4 years of follow-up were 85.3, 82.6, 80.1 after total arthroplasty, hemi-arthroplasty and internal fixation respectively. Similarly, the Harris Hip Scores after 4 years of follow-up were 83.7, 79.5 and 73.6. The range of passive hip motion in the three groups of patients did not differ significantly $(p>0.05)$. Also, patients of the total arthroplasty and hemi-arthroplasty groups walked faster than the patients of the internal fixation group 4 years after discharge $(p<0.05)$. In conclusion, we believe that total hip arthroplasty is the treatment of choice for displaced subcapital hip fractures in patients over 70 years old.

Résumé Selon la littérature, la fonction de la hanche après traitement d'une fracture dépend du type d'intervention. Le but de notre étude est d'apprécier la corrélation qui existe entre le traitement chirurgical et la fonction post-opératoire chez les patients âgés. Les critères d'inclusion ont été la notion d'une fracture déplacée chez les patients âgés de plus de 70 ans. Cent vingt-neuf patients ont été randomisés en trois groupes selon le type d'intervention, prothèse intermédiaire de type Merete, prothèse totale de type Plus et fixation interne par vis plaque de type Richards. La fonction des patients a été estimée selon les paramètres suivants : index de Barthel, Score de Harris, mobilité passive de la hanche et vitesse de marche après un à quatre ans de suivi. Le score de Barthel à quatre ans, post opératoire est passé respectivement à $85,3,82,6,80,1$ après 
prothèse totale, prothèse intermédiaire et fixation interne, de même en ce qui concerne le score de Harris qui est passé respectivement de 83,7, 79,5, 73,6. La mobilité passive de la hanche dans les trois groupes ne montre pas de différence significative. Les patients ayant bénéficié d'une prothèse totale ou d'une prothèse intermédiaire ont une marche plus rapide que les patients ayant bénéficié d'une fixation interne $(p<0.05)$. En conclusion, nous pensons que la prothèse totale de hanche est le traitement de choix pour les fractures déplacées sous capitale de la hanche chez les patients de plus de 70 ans.

\section{Introduction}

Displaced subcapital hip fractures are difficult injuries associated with increased mortality and high hospitalisation costs. Their treatment aim for the restoration of the patient's function to the same level as before the fracture and avoidance of possible complications of the fracture.

The prognosis for functional recovery following displaced subcapital fractures depends on the patients' preexisting health status. These fractures only have a good prognosis if the patient had a good performance before the fracture and is free of other pathological or psychiatric conditions [8, 9, 23, 25]. In addition, better outcome is reported when the fracture occurs in a male patient aged less than 75 years $[13,14,26]$. Also, the level of the patient's social support is important in the achievement of good functional rehabilitation [19, 22].

Many studies have attempted to define the relationship between the type of operation and the functional restitution of the patient. The selection of the proper surgical procedure is an ambiguous matter for many researchers $[6,11,20]$.

In the literature three types of surgical treatment for these fractures are reported, including total arthroplasty, hemiarthroplasty and internal fixation. However, few researchers refer to the impact of these methods on the functional rehabilitation of the patient.

Despite surgical management, $10-20 \%$ of patients do not achieve automatic and functional mobility up to 1 year after the injury [7]. It is reported that only $43 \%$ of patients manage to reach preoperational levels of function 2 months after the operation, while 1 month later, mobility still remains reduced in $20-25 \%$ [4, 5, 10]. Usually, 2 months after the operation none of the patients is in pain, although cases are reported in which, 12-14 months after the operation, $27 \%$ of patients still have hip pain $[4,10]$.

Consequently, we realise that patients with fracture of the hip joint are functionally dependant for a long period, a fact that increases the economic cost of their hospitalisation.
We hypothesised that total arthroplasty might offer better functional outcome; thus, we tried to estimate the functional restitution of the patients up to 4 years after the surgical treatment of a displaced subcapital hip fracture, comparing the three surgical options.

\section{Materials and methods}

Patients with displaced subcapital hip fracture (Garden III or IV) after falling down and having treatment in our hospitals from April 1999 to April 2002 were evaluated. From a population of 387 patients who were admitted, 129 patients were randomly selected for our prospective study (one patient was selected every third admission).

Furthermore, these 129 participants were randomly divided, by two orthopaedic surgeons, into three groups according to the type of the surgical operation they were to undergo, following this order: hemi-arthroplasty (Merete, Berlin, Germany), total arthroplasty (Plus; De Puy, Warsaw, IN, USA), internal fixation (Richards plate-screw; Smith \& Nephew, Memphis, TN, USA), etc.

Exclusion criteria included previous hip fracture, history of cancer or Paget's disease, or rheumatic arthritis.

Postoperatively in the hospital and after discharge, all patients received the same rehabilitation programme, including strengthening exercises mainly for hip flexors, extensors, abductors and knee extensors, and range-ofmotion (ROM) exercises for the hip and knee joint. Data on the rehabilitation programme (of 2 months' duration after discharge) was monitored by the observations of relatives.

All patients were informed of their inclusion in the study and signed a consent form. Information collected during the hospital stay included demographic data, medical complications and time to surgery. Health status before hip surgery was evaluated by the American Society of Anaesthesiology (ASA) score. Cognitive status was assessed by the Short Portable Mental Status Questionnaire (score range 0-10).

The function of the patients was estimated with the use of the following parameters:

1. Barthel Index and Harris Hip Score

2. Range of passive hip motion

3. Gait speed of individuals

The Barthel Index is a questionnaire that consists of ten questions measuring the ability of the patient to achieve daily activities such as independance and walking without help. The questionnaire is characterised by a validity coefficient of 0.73 0.77 and a credibility coefficient ranging from 0.87 to 0.96 $[23,24]$. The maximum score that can be achieved is 100 .

Shah et al. proposed the following explanation for different scores: $0-20=$ complete dependency of the patient, $21-60=$ serious dependency of the patient, $61-90=$ moderate 
dependency of the patient, 91-99 = little dependency of the patient and $100=$ complete independence of the patient.

The Harris Hip score includes four thematic issues, which refer to: pain, mobility, daily activities and range of movement. The questionnaire is characterised by a validity coefficient for pain of 0.64 , for functionality of 0.95 , for range of movement of 0.33 and for anatomical alignment of 0.87 , and with coefficient of credibility 0.94 [17]. The issue of pain is scored $0-44$, functionality is scored $0-47$, range of motion from $0-5$ and anatomical alignment $0-4$. The Harris Hip Score results were categorised as excellent (90-100), good (80-89), fair (70-79) and poor (69 points or less).

Two trained interviewers, blinded to the type of surgery, assessed the questionnaires. In our study the following were completed:

1. The Barthel Index questionnaire, three times. The first concerned the functionality of the patient before the fracture and the other two concerned the function 1 and 4 years after the surgical treatment of the patient.

2. The Harris Hip Score questionnaire was carried out only twice to measure function 1 and 4 years respectively after surgical treatment.

Furthermore, patients were evaluated for hip range of passive motion with a goniometer and walking velocity was measured in hospital according to the distance each patient walked and the time he/she took to complete the task. For example, the time needed to walk $20 \mathrm{~m}$.

Statistical analysis was performed with SPSS, version 11.0. Two-way analysis of variance (ANOVA) with repeated measures to compare the differences between the three groups and among the different stages. The significance level was set at 0.05 .

129 patients

initially participated in the study

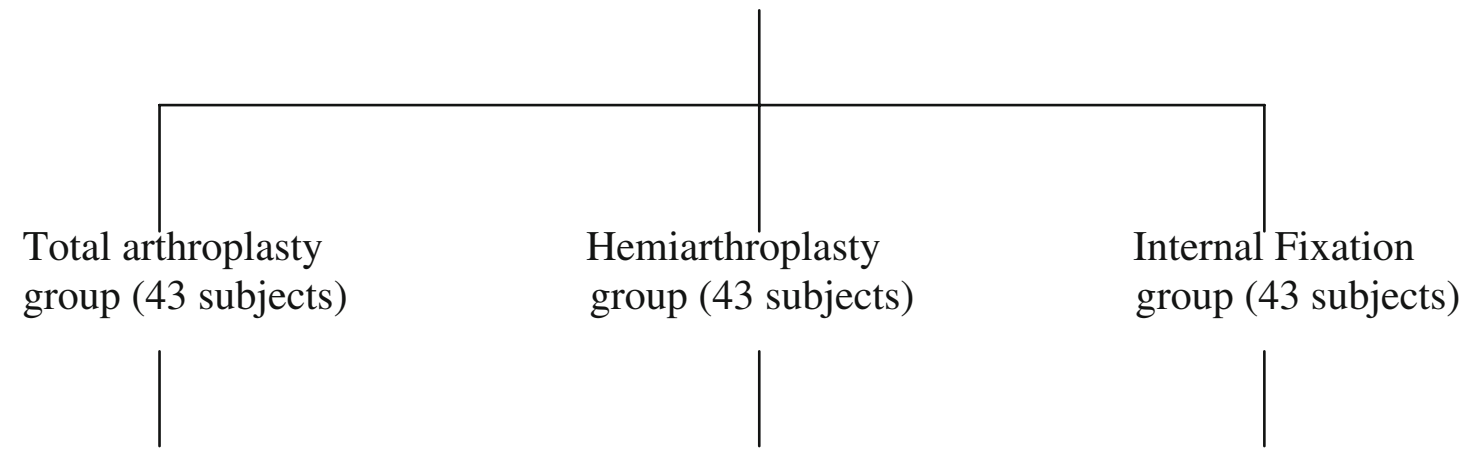

excluded $\quad 2$ : previous hip fracture

6: died

2: data lost<smiles>C1CCCC1</smiles>

at 1-year

follow-up

33 (subjects)<smiles>C=CC</smiles>

excluded

9: died

1: revised

at 4-year

follow-up 23(subjects)

Fig. 1 Flow diagram of patients' treatment and outcome
5: previous hip fracture

6: died

2: revised<smiles>C1CCCCC1</smiles>

30 (subjects)<smiles>[CH]=C</smiles>

7: died

3: revised

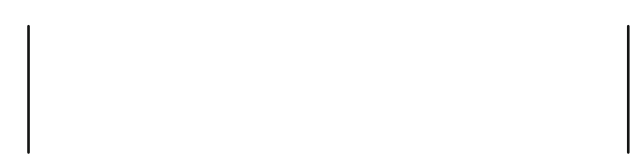

20(subjects)
1: previous hip fracture

5: died

5: revised

\section{2 (subjects)}

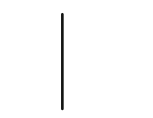

6: died

7: revised

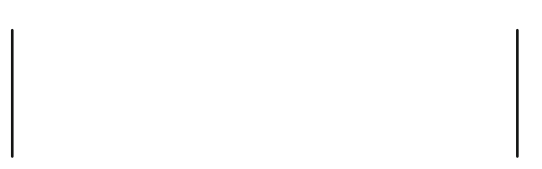

19(subjects) 
Table 1 Features of the 129 patients enrolled in the study

\begin{tabular}{lccc}
\hline Variable & $\begin{array}{l}\text { Total } \\
\text { arthroplasty }\end{array}$ & $\begin{array}{l}\text { Hemi- } \\
\text { arthroplasty }\end{array}$ & $\begin{array}{l}\text { Internal } \\
\text { fixation }\end{array}$ \\
\hline Number of participants & 37 & 34 & 38 \\
Age & $73.07 \pm 4.93$ & $74.24 \pm 3.77$ & $75.38 \pm$ \\
& & & 4.62 \\
Males & 9 & 10 & 12 \\
Females & $2.03 \pm 1.97$ & $2.21 \pm 1.9$ & $1.96 \pm 1.1$ \\
ASA score & $7.9 \pm 2.6$ & $7.5 \pm 3.1$ & $7.8 \pm 2.8$ \\
Cognitive status (SPMSQ) & 37 & 34 & 38 \\
Ambulatory & $45.2 \pm 7.3$ & $45.8 \pm 2.4$ & $44.2 \pm 5.2$ \\
Mean preoperative & & & \\
waiting time & 1 & 0 & 1 \\
Living in own house & 36 & 34 & 37 \\
Living with relatives & 0 & 0 & 0 \\
Living in nursing home & $8.3 \pm 6.2$ & $9.1 \pm 3.4$ & $13 \pm 2.8$ \\
Length of hospital stay & & & \\
\hline
\end{tabular}

SPMSQ Short Portable Mental Status Questionnaire

\section{Results}

Eight patients who had sustained previous contralateral hip fracture were excluded from the study. During the first year of follow-up after discharge, 17 patients died (6 from the hemi-arthroplasty group, 6 from total arthroplasty group and 5 from the internal fixation group). Additionally, 2 patients (from the total arthroplasty group) moved to another country so it was not possible to collect data for their post-operative progression. Furthermore, 5 patients from the internal fixation group and 2 patients from the hemi-arthroplasty group were revised with total arthroplasty and were excluded from the study.

During the 4-year follow-up period, 15 patients from the total arthroplasty group, 13 patients from the hemiarthroplasty group and 11 patients from the internal fixation group respectively died. In addition, 1 total arthroplasty, 3 hemi-arthroplasties and 7 internal fixations were revised.

Therefore, the functional performance was evaluated in 95 and 62 patients, 1 and 4 years after operation respectively (Fig. 1).

The basic demographic and medical data of the three groups are listed in Table 1. The three study groups did not significantly differ statistically except with regard to the length of hospital stay.

Estimation of function with the Barthel Index score

The levels of patients' performance according to the Barthel Index score are presented in Table 2.

According to the Barthel Index Score the internal fixation group had the worst function 1 and 4 years after discharge $(p<0.05)$.

About two out of three patients who were operated up on by total arthroplasty managed to regain the same performance as they had before the fracture, while $31 \%$ of patients, 4 years after the treatment had worse performance in comparison with the period before the fracture. Those with the worst performance struggled to bath themselves alone (36\%) and to dress themselves without help (27\%). In any case, total arthroplasty offers good performance since after the operation no statistically significant difference is observed between the initial prefracture and final performance, 4 years after hip surgery $(p>0.05)$.

In addition, one to two patients who were operated up on with hemi-arthroplasty managed to achieve the same performance as that before the fracture, while $38 \%$, performed worse 4 years after the procedure, in comparison with the period before the fracture. Mainly, the patients find it hard to bath themselves alone (31\%) and to get dressed without help (26\%), the same as the total arthroplasty group. Additionally, performance observed 4 years after the therapy does not significantly differ from that before the fracture $(p>0.05)$.

On the contrary, in the group with internal fixation only $28.5 \%$ regained the same performance as that they had before the fracture. The patients also struggled in the ability to bath themselves without help (59\%), to get dressed without help (68\%) and to climb stairs (23\%). Internal fixation is the only surgical procedure that has statistically significantly worse performance after the fracture repair than during the period before the fracture $(p<0.05)$.

By the time all patients improved their functional performance, only the patients of the internal fixation group were unable to reach prefracture levels.
Table 2 Patients' prefracture and post-fracture repair functionality according to the Barthel Index Score

*Statistical significance comparing the functionality before and after fracture in each group, $p<0.05$

\begin{tabular}{lccc}
\hline & Total arthroplasty group & Hemi arthroplasty group & Internal fixation group \\
\hline $\begin{array}{l}\text { Prefracture function } \\
\text { (129 patients) }\end{array}$ & $87.4 \pm 17.4$ & $81.05 \pm 8.95$ & $85.2 \pm 4.8$ \\
Function at discharge & $62.3 \pm 3.4^{*}$ & $62.1 \pm 5.7^{*}$ & $60.3 \pm 2.6^{*}$ \\
Function after 1 year & $84.8 \pm 14.8$ & $76.8 \pm 6.8$ & $77.1 \pm 7.1^{*}$ \\
$\quad(95$ patients) & $85.3 \pm 11.6$ & $79.6 \pm 6.3$ & $80.1 \pm 5.3^{*}$ \\
Function after 4 years & & & \\
$(62$ patients) & & & \\
\hline
\end{tabular}


Estimation of functionality with Harris Hip score

Almost one half (56\%) of the total arthroplasty group, 37\% of patients with hemi-arthroplasty and $26.6 \%$ of patients with internal fixation achieved a score above 80 in the Harris Hip Score system. The best functional level seems to belong to total arthroplasty of the hip joint and the worst to internal fixation (Table 3). Total arthroplasty offers best function and the effectiveness of the procedure is statistically significantly better than internal fixation, 4 years after hip surgery $(p<0.05)$. In addition, the results of hemiarthroplasty are not significantly different from those of total arthroplasty or those from internal fixation $(p>0.05)$. Despite functional improvement in time, the internal fixation group is associated with poor functional outcome.

Plus, the incidence of pain is greater in the internal fixation group $(p<0.05)$. About $35 \%$ of patients in this group experienced pain, mainly slight pain, during the follow-up of 4 years.

\section{Estimation of range of motion and walking speed}

The range of passive hip motion in the three groups of patients does not differ significantly $(p>0.05)$. None of the above-mentioned surgical procedures affects hip motion. But more poor results were observed after internal fixation. Hip flexion seems to be more affected after internal fixation and the rotation movements were better in the hemiarthroplasty group. Concerning the walking speed, it was found that the patients of the total arthroplasty and hemiarthroplasty groups walked faster than the patients of the internal fixation group 4 years after discharge $(p<0.05)$.

\section{Significant correlations between variables}

The Barthel Index score and the Harris Hip score, after 1 year of follow-up, were strongly correlated with age at the time of injury ( $r=0.72$ and $\mathrm{r}=0.78$ respectively, $p<0.05$ ), cognitive status ( $r=0.75$ and $r=0.78$ respectively, $p<0.05$ ), and prefracture Barthel Index score $(r=0.82$ and $r=0.8$ respectively), for the whole group of patients.

Table 3 Harris Hip Score after surgical treatment of displaced subcapital hip fracture. Comparison among three groups at one and four years after discharge

\begin{tabular}{lccc}
\hline & $\begin{array}{l}\text { Total arthroplasty } \\
\text { group }\end{array}$ & $\begin{array}{l}\text { Hemi-arthroplasty } \\
\text { group }\end{array}$ & $\begin{array}{l}\text { Internal } \\
\text { fixation }\end{array}$ \\
\hline At discharge & $59.4 \pm 5.8$ & $58.3 \pm 6.2$ & $58.1 \pm 5.3$ \\
1 year & $81.6 \pm 4.9$ & $77.81 \pm 9.6$ & $71.3 \pm 5.3^{*}$ \\
4 years & $83.7 \pm 4.8$ & $79.5 \pm 6.5$ & $73.6 \pm 6.7^{*}$ \\
\hline
\end{tabular}

* Statistically significant difference between the total arthroplasty and internal fixation groups
At the same time, pain was significantly correlated with walking speed $(r=0.86, p<0.05)$. Also, pain was significantly associated with the ability to bathe and get dressed independently ( $r=0.78$ and $r=0.83$ respectively). At the 4-year follow-up the above correlations were not observed.

\section{Discussion}

The optimal treatment for displaced subcapital hip fractures in elderly patients is a matter of controversy [15, 21]. Surgical treatment options include reduction and internal fixation, unipolar hemi-arthroplasty or bipolar hemi-arthroplasty, and total hip arthroplasty [12].

Internal fixation is usually recommended for most undisplaced fractures of the femoral neck. In addition, internal fixation could be used for the treatment of displaced subcapital hip fractures if the hip joint space is normal without extensive degenerative changes, or a satisfactory reduction of the fracture is achieved within 24 hours [6, 20].

If urgent reduction of displaced femoral neck fractures cannot be achieved because of fracture complexity, poor medical condition, or poor bone quality, the best option for patients who are ambulatory is total hip arthroplasty. Furthermore, total hip replacement for displaced femoral neck fractures has been reserved for patients with preexisting arthritic hip disease, Paget's disease, renal osteodystrophy, and severe osteoporosis, those patients with high activity expectations or life expectancy greater than 5 years, and after failed internal fixation [12, 16, 21].

Alternatively hemi-arthroplasty should be recommended for patients with cognitive problems and little or no walking capability. Bipolar hemi-arthroplasty in particular should be used for patients with instability risks, such as neurological impairment [12].

Our study was prospective and randomised, comparing the three alternative treatment modalities in displaced femoral neck fractures by focussing on functional recovery.

Until now there have been few randomised studies comparing total arthroplasty with hemi-arthroplasty and internal fixation simultaneously in these patients. Most of them have revealed that total arthroplasty is associated with better functional outcomes than the other methods.

In a prospective randomised study, Ravikumar and Marsh compared three methods of treatment including internal fixation with a sliding compression screw plate, uncemented hemi-arthroplasty and cemented total hip arthroplasty for displaced subcapital hip fractures [17]. After 1 year, $27 \%$ of patients treated with hemi-arthroplasty and $12 \%$ treated with internal fixation complained of significant hip pain, although no patients treated with total 
hip arthroplasty complained of pain. The authors concluded that both internal fixation and hemi-arthroplasty resulted in poor outcomes with regard to pain and mobility.

Similarly, Rogmark et al. found after 2 years' follow-up that $36 \%$ of patients who had undergone internal fixation had impaired walking and $6 \%$ of them complained of severe pain [18]. On the other hand, $25 \%$ of patients who had undergone total arthroplasty or hemi-arthroplasty had impaired walking and only $1.5 \%$ of them complained of severe pain.

Furthermore, Skinner et al. found that total hip arthroplasty resulted in the least pain and most mobility, while hemi-arthroplasty produced the worst results after 1 year's follow-up [20]. The authors concluded that total hip arthroplasty and internal fixation should be given serious consideration in the management of the elderly patient with a displaced subcapital fracture.

More patients treated with hemi-arthroplasty are able to walk equally as well as before the fracture and experience no pain on weight-bearing after 4 months than those treated with internal fixation [3].

In contrast, Bhandari et al., in a meta-analysis of 14 clinical studies, showed no difference between treatment with internal fixation or arthroplasty with regard to postoperative pain and function [1].

According to the Barthel Index Score and Harris Hip Score, internal fixation is associated with statistically significantly worse performance after the fracture repair after 1 and 4 years of follow-up than in the prefracture period. Most of the patients are unable to bathe themselves and to get dressed independently, mainly because of pain. Comparing the passive range of motion, no statistically significant differences were found among the three procedures, which probably means that patients who were treated with internal fixation find daily activities difficult because of pain.

As a matter of fact, patients who were treated with internal fixation had the advantage of saving the natural joint if healing succeeds, but develop poor rehabilitation because of residual pain until the fracture has healed and because of the high rate of osteosynthesis failure. On the other hand, arthroplasty offers better stability and allows patients to move with less pain. Patients are permitted to bear full weight immediately after implantation, thus maximising mobilisation and the rehabilitation potential of the patient.

In addition, there were no statistically significant differences between total hip arthroplasty and hemi-arthroplasty with regard to functional outcome. Although hemi-arthroplasty can offer a satisfactory outcome for these fractures, total hip arthroplasty is a more functional and cost-effective procedure, because it is associated with less pain and low reoperation rates. Furthermore, total hip arthroplasty, apart from fracture repair, provides a treatment for possible coexistent hip osteoarthritis.

Our study consisted of patients aged 70 years or more, who had a good cognitive status and moderate dependency. In conclusion, we recommend total arthroplasty as the treatment of choice for displaced subcapital hip fractures.

\section{References}

1. Bhandari M, Devereaux P, Swiontkowski M, Tornetta P, Obremskey W, Koval K, Nork S, Sprague S, Schemitsch E, Guyatt G (2003) Internal fixation compared with arthroplasty for displaced fractures of the femoral neck. A meta-analysis. J Bone Joint Surg Am 85A (9):1673-1681

2. Ceder L, Thorngren G, Wallden B (1980) Prognostic indicators and early home rehabilitation in elderly patients with hip fractures. Clin Orthop 152:173-184

3. Cserhati P, Fekete K, Berglund-Roden M, Wingstrand H, Thomgren K (2002) Hip fractures in Hungary and Swedendifferences in treatment and rehabilitation. Int Orthop 26(4):222228

4. Cuckler JM, Tamarapalli JR (1994) An algorithm for the management of femoral neck fractures. Orthopedics 17(9):789792

5. Cummings R, Phillips L, Wheat E, Black D, Goosby E, Wlodarczyk D, Trafton P, Jergesen H, Winograd C, Hulley S (1988) Recovery of function after hip fracture. The role of social supports. J Am Geriatr Soc 36(9):801-806

6. Davidson CW, Merrilees MJ, Wilkinson TJ, Mckie J, Gilchrist N (2001) Hip fracture mortality and morbidity - can we do better? N Z Med J 114(1136):329-332

7. Haentjens P (2003) Costs of care after hospital discharge among women with a femoral neck fracture. Clin Orthop 1(414):250-258

8. Harris HW (1969) Traumatic arthritis of the hip after dislocation and acetabular fractures: treatment by Moore arthroplasty. An end result study using a new method of result evaluation. J Bone Jt Surg Am 51:737-755

9. Healey W, Iorio R (2004) Hip arthroplasty: optimal treatment for displaced femoral neck fractures in elderly patients. Clin Orthop 429:43-48

10. Koval J, Zuckerman D (1994) Hip fractures. I. Overview and evaluation and treatment of femoral neck fractures. J Am Acad Orthop Surg 2:141-149

11. Koval J, Skovron L, Aharnoff B, Zuckerman J (1998) Predictors of functional recovery after hip fracture in the elderly. Clin Orthop 348:22-28

12. Lu-Yao GL, Keller RB, Littenberg B, Wennberg J (1994) Outcomes after displaced fractures of the femoral neck. A metaanalysis of one hundred and six published reports. J Bone Jt Surg Am 76(1):15-25

13. Magaziner J, Simonsick M, Kashner M, Hebel J, Kenzora J (1990) Predictors of functional recovery one year following hospital discharge for hip fracture: a prospective study. J Gerontol 45(3):101-107

14. Marottoli A, Berkman F, Cooney M (1992) Decline in physical function following hip fracture. J Am Geriatr Soc 40(9):861-866

15. Mossey M, Murtan E, Knott K, Graik R (1989) Determinants of recovery 12 months after hip fracture: the importance of psychological factors. Am J Public Health 79(3):279-286

16. Parker J, Pryor A (2000) Internal fixation or arthroplasty for displaced cervical hip fractures in the elderly: a randomised controlled trial of 208 patients. Acta Orthop Scand 71:406-440 
17. Ravikumar KJ, Marsh G (2000) Internal fixation versus hemiarthroplasty versus total hip arthroplasty for displaced subcapital fractures of femur -13 year results of a prospective randomised study. Injury 31:793-797

18. Rogmark C, Carlsson A, Johnell O, Sembo I (2002) A prospective randomised trial of internal fixation versus arthroplasty for displaced fractures of the neck of the femur. Functional outcome for 450 patients at two years. J Bone Joint Surg Br 84 (2): $183-188$

19. Shah S, Vanclay F, Cooper B (1989) Improving the sensitivity of the Barthel Index for stroke rehabilitation. J Clin Epidemiol 42:703-709

20. Skinner P, Riley D, Ellery J, Beaumont A, Cumine R, Shafighian B (1989) Displaced subcapital fractures of the femur: a prospective randomized comparison of internal fixation, hemi-arthroplasty and total hip replacement. Injury 20:291-293
21. Su H, Aharonoff GB, Hiebert R, Zuckerman J, Koval K (2000) Inhospital mortality after femoral neck fracture: do internal fixation and hemi-arthroplasty differ? Am J Orthop 32(3):151-155

22. Swiontkowski F (1994) Current concepts review: intracapsular fractures of the hip. J Bone Jt Surg 76A:129-138

23. Tanaka J, Tokimura F, Seki N (2003) Outcomes of hip fracture surgery in patients aged $>$ or $=90$ years. Orthopedics 26(1):55-58

24. Wade T, Collin C (1988) The Barthel ADL Index: a standard measure of physical disability? Int Disabil Stud 10:64-67

25. Young Y, German P, Brandt L, Kenzora J, Magaziner J (1996) The predictors of surgical procedure and the effects on functional recovery in elderly with subcapital fractures. J Gerontol A Biol Sci Med Sci 51:158-164

26. Young Y, Brandt L, German P, Kenzora J, Magaziner J (1997) A longitudinal examination of functional recovery among older people with subcapital hip fracture. J Am Geriatr Soc 45(3):288-294 